\title{
Effect of coal on mine tailings' water permeability and water retention
}

\author{
Andrew Vidler $^{1, *}$, Olivier Buzzi ${ }^{1}$, and Stephen Fityus ${ }^{1}$ \\ ${ }^{1}$ Priority Research Centre for Geotechnical Science and Engineering, Faculty of Engineering and Built Environment, The University of \\ Newcastle, Callaghan, NSW, Australia
}

\begin{abstract}
For safe and efficient mining operations to occur the management of waste materials is required, which often takes the form of geotechnical structures constructed from this waste. The safe use of these structures requires a number of resources, one of these being sufficient information about the waste material properties. For example, the drying process of a tailings dam is predicted with the water retention and permeability of the tailings. When considering coal tailings, which are comprised of coal and mineral soil particles (typically), the presence of coal may be problematic. The localised hydrophobicity of coal molecules may have a unique effect on water permeability and retention; this is relevant to geotechnical analysis where hydrophilic behaviour is assumed. To explore the possible effect of localised hydrophobicity, mine tailings were obtained from a coal mine of the Hunter Valley, NSW, Australia, and the coal fraction was separated via density separation. After this, three materials were available: unchanged mine tailings and a coal and mineral fraction of tailings. The goal was to characterise the three materials and allow deeper insight on what effect the addition of coal has on retention and hydraulic properties. Characterization involved measuring particle size distribution, pore size distribution, soil water retention curve, and saturated water permeability. The results show that there are distinct differences in the water retention and permeability properties of each material, and a number of these differences could be explained by the differing particle/pore sizes observed in each material. However, the coal containing materials desaturated at low suctions $(<10 \mathrm{kPa})$ compared to the mineral fraction, which could not be explained by particle/pore size differences and points towards localised hydrophobicity as a possible cause.
\end{abstract}

\section{Introduction}

Mining is prevalent in modern society and managing mine waste requires adequate strategies and safe design of structures such as spoil piles or tailings dams. One problematic waste material is coal tailings, a residue of the beneficiation process of coal, which is a fine grained material with a significant amount of coal. Coal is a material of highly heterogeneous chemical composition that is formed naturally $[1,2]$. Coal contains various organic components called macerals. A maceral can be considered analogous to a mineral in rocks. The specific gravity (Gs) of macerals and consequently coal, varies from 1.1 to 1.5 [3]. Coal molecules can be described as aromatic hydrocarbon molecules with a number of different functional groups attached, such as Hydroxyl and Carboxyl.

It is common for coal tailings to be placed in a tailings dam, and these are often capped to try to make use of the land. However, capping is a delicate geotechnical operation for which it is relevant to know the rate at which tailings will dry upon environmental conditions. Estimating drying rates requires an estimate of water retention properties and the permeability function. Some of the functional groups in coal molecules can be hydrophobic while other surface areas are hydrophilic [4]. As a result, coal is often considered as more hydrophobic than common soils [4-8] but not purely hydrophobic. This view is supported by contact angle measurements on common coal macerals varying from $25-130^{\circ}$ [9], whereas typical minerals in soil only have a contact angle between $20-40^{\circ}$ [10]. This relative hydrophobicity is very significant for hydraulic and retention properties, in particular in the context of unsaturated soil mechanics where experiments and models are developed on hydrophilic soil particles. Indeed, little information is available in the literature on hydrophobic soils in the context of geotechnical engineering. This paper presents the preliminary results of an experimental study on the effect of coal localised hydrophobicity on hydraulic and retention properties of coal tailings.

\section{Materials and methods}

Coal tailings produced by a coal mine of the Hunter Valley, NSW, Australia, was used for this study. The coal fraction was separated from the mineral fraction of the tailings in order to test three materials: the original

Corresponding author: Andrew.vidler@uon.edu.au 
mine tailings, a coal fraction and a mineral fraction. Characterizing these materials individually can allow deeper insight on how addition of coal to a mineral soil affects retention and hydraulic properties.

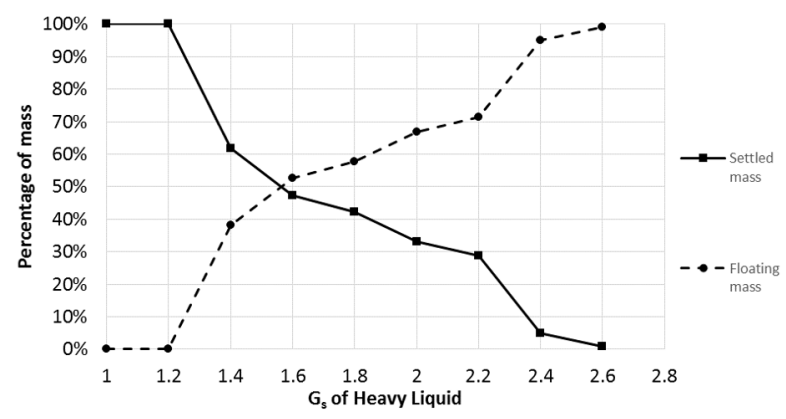

Fig. 1. Distribution of Gs for the particles in coal tailings.

The saturated water permeability, soil water retention curve (SWRC), grain size distribution (GSD) and pore size distribution (PSD) were determined for each material. The objective of the testing program is to assess whether an effect from the localised hydrophobicity of coal can be observed on retention and hydraulic properties.

The separation of minerals and macerals was performed with density separation using a "heavy liquid" (lithium heteropolytungstate solution), which can have its Gs adjusted to any value below 2.85. The separation was accelerated via a centrifuge. Given that macerals are known to have a Gs in the range of 1.1 to 1.5 while for minerals, it is in the range 2.6 to 2.7 , the separation process was used as a tool to determine what fraction of the tailings was coal (floating fraction) and minerals (sedimented fraction). Thus, for a variety of heavy liquids with differing Gs values, the mass of the floating and sedimented fractions were measured.

Following this process, two separation operations were conducted with a heavy liquid Gs of 1.4 and 2.2, in order to obtain "clean" fractions of coal and minerals. After separation, the material was cleaned with deionised water to remove chemical residue from the heavy liquid.

Once the three materials were gathered basic characterization of each material was done, where the Gs and GSD was measured. The Gs measurements were performed using a gas pycnometer, on material which was prepared to a dry powder with particle size $<75 \mu \mathrm{m}$. The GSD was measured via the laser diffraction method, on material prepared to a loose and dry condition, as dispersion of soil particles occurs during the test procedure.

To assess an effect from the localised hydrophobicity of coal the following was measured: PSD, SWRC and saturated water permeability.

The PSD was obtained with mercury intrusion porosimetry, which was performed on samples of each material (size of $\approx 1 \mathrm{~cm} 3$ ) prepared to a void ratio of $\approx 1$ via consolidation from a slurry. Following this, the samples were cut to small cubes $(\approx 1 \mathrm{~cm} 3)$ then freezedried to remove the water and preserve the pore microstructure.
The SWRC of each material was constructed from suction measurements on a sample undergoing drying, and the relationship of the soil bulk volume with gravimetric water content (w). Suction was measured using either a high capacity tensiometer $(<1.5 \mathrm{MPa})$ or a dewpoint potentiameter $(>1.5 \mathrm{MPa})$. The sample undergoing drying was prepared to an initial void ratio of $\approx 1$ via consolidation from a slurry. The $\mathrm{w}$ of the sample was monitored via mass measurements and dried incrementally using a $60{ }^{\circ} \mathrm{C}$ oven. An equilibration time of at least 2 days was given after a drying step before taking a suction measurement; to avoid drying during equilibration, the samples were vacuum sealed in plastic.

The hand spray plaster method was used to determine the bulk volume to water content relationship, a detailed description of the procedure can be found in the literature [11] and only a brief description is given in this paper. The procedure involves coating an initially saturated soil sample (size $\approx 1 \mathrm{~cm} 3$ ) in a waterproof material, which is also permeable to water vapour (to allow drying of the sample). The volume of the sample is measured by submersion in an oil and use of Archimedes' principle. A sample of each material (initial void ratio $\approx 1$ via consolidation from a slurry) was progressively dried and its volume measured to obtain the relationship. The relationship allowed the drying SWRC be expressed in terms of volumetric water content $(\theta)$ and saturation ratio $(\mathrm{Sr})$.

Measurements of saturated water permeability were performed using a constant head permeameter with samples held at constant volume. The samples of each material were prepared to a void ratio of $\approx 1$ via compaction from a dry powder. A different preparation process was adopted due to the sample sizes from consolidation being incompatible with the permeameter. Following this, the sample was saturated (in the

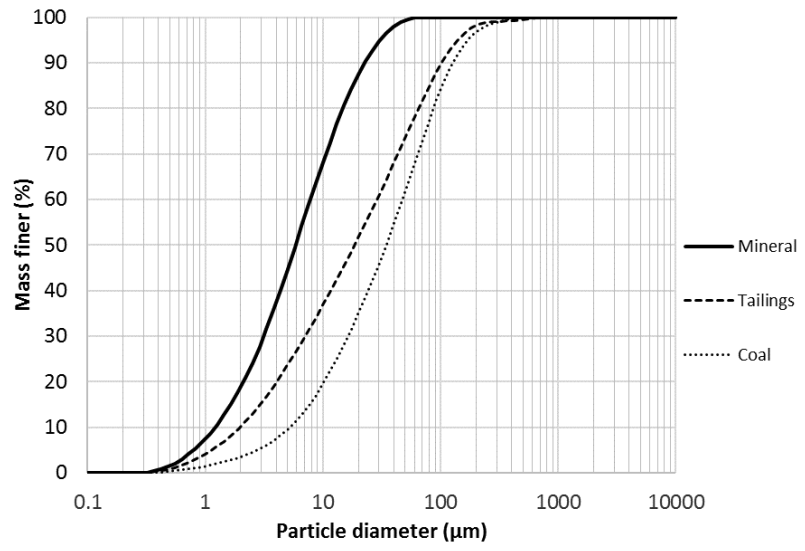

Fig. 2. Grain size distributions of each material. Note, the mineral and coal fractions were extracted from the tailings.

permeameter) by applying a water pressure gradient until the flow rate was constant.

\section{Results and discussion}

The results of this section are separated into a number of categories; results of the separation process, and results 
related to microstructure, water retention and permeability properties.

\subsection{Separation outcomes}

The $G_{s}$ distribution found for the tailings is shown in Figure 1, which suggests that there is no clear boundary between the maceral and mineral fractions of the tailings. Indeed, progressively increasing the specific gravity of the heavy fluid results in a progressive

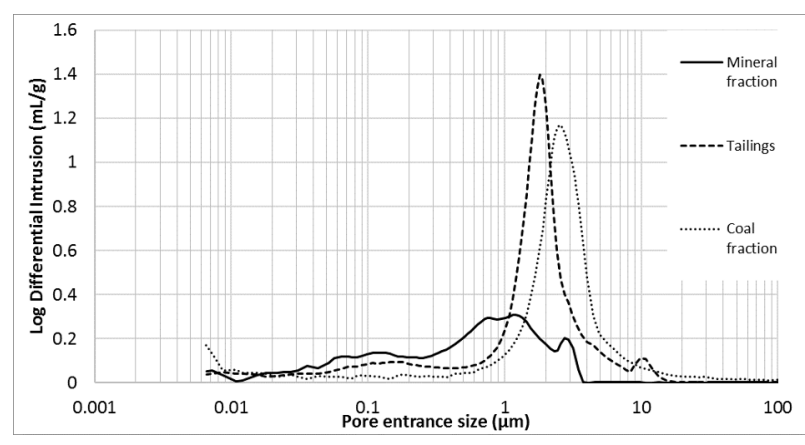

Fig. 3. Pore size distributions of each material (void ratio $\approx 1$ ).

increase of floating fraction. Thus, after reviewing Figure 1 and given that the specific gravity of macerals typically falls in the range 1.1 to 1.5 , it was deemed that particles with a $\mathrm{G}_{\mathrm{s}}$ below 1.4 were predominately macerals, and those above 2.2 were predominately minerals. The remainder of the particles between $\mathrm{G}_{\mathrm{s}} 1.4$ and 2.2 are likely comprised of both macerals and minerals and were not considered on their own, in this study.

Table 1. $\mathrm{G}_{\mathrm{s}}$ of the materials.

\begin{tabular}{|c|c|}
\hline Material & $\mathbf{G}_{\mathbf{s}}$ \\
\hline $\begin{array}{c}\text { Tailings (particle } \\
\text { average) }\end{array}$ & 1.81 \\
\hline Coal fraction & 1.39 \\
\hline Mineral Fraction & 2.63 \\
\hline
\end{tabular}

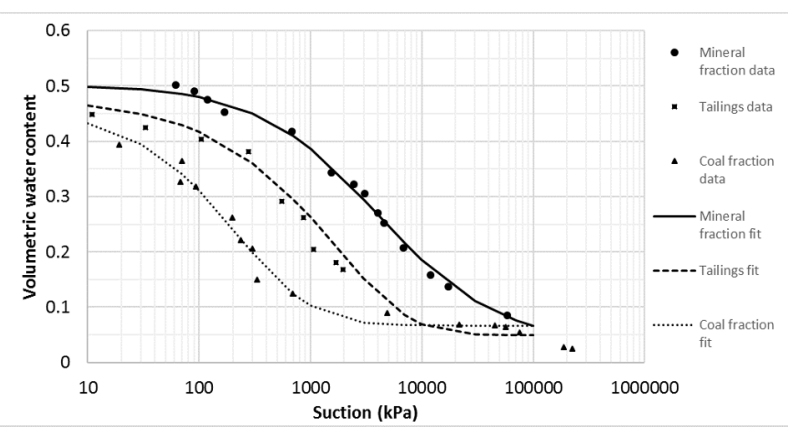

Fig 4. Soil water retention curve of the materials in terms of $\theta$.

Following the separation processes at a Gs of 1.4 and 2.2, each material had its specific gravity measured. Results are reported in Table 1.
The GSD of each material is shown in Figure 2. The coal fraction was found to be coarser than the original tailings, which is itself, coarser than the mineral fraction.

\subsection{Microstructure results}

The PSD of the materials was measured as it is relevant to interpret the permeability and SWRC results of each material. Results are presented in Figure 3.

The pore size distribution of all three materials was found to be monomodal with a predominant pore size of $1.9 \mu \mathrm{m}, 2.5 \mu \mathrm{m}$ and $1 \mu \mathrm{m}$, for the tailings, the coal and minerals, respectively. In contrast to the tailings and coal

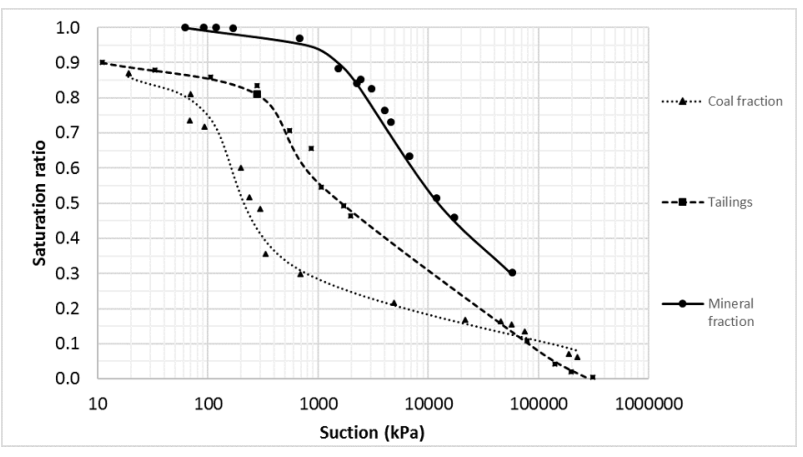

Fig 5. Soil water retention curve of the materials in terms of $S_{\mathrm{r}}$.

fraction which have a very pronounced peak, the density of the dominant pores is low for the minerals, resulting in a very low peak.

For all three materials, the dominant pore size is consistent with the grain size distribution: the coarser the material, the larger the dominant pore size. Figure 3 also shows that there are no pores with an entrance size larger than $20 \mu \mathrm{m}$, which is relevant to findings about saturated permeability, as will be discussed later.

\subsection{Water retention results}

The drying branch of the retention curve is shown, for each material, in figures 4 and 5 , in terms of volumetric water content $\theta$ and degree of saturation $\mathrm{S}_{\mathrm{r}}$, respectively.

Although measurements on the samples consolidated from slurry with suctions below $10 \mathrm{kPa}$ suction were attempted, these are not shown in figures 4 and 5. This is because of the significant relative error associated with the resolution of the high capacity tensiometers when used to measure very low suctions $(+-7 \mathrm{kPa})$. The degree of saturation and corresponding water content in the coal and tailings samples at the end of consolidation are presented in Table 2.

Table 2. Values of gravimetric water content, volumetric water content and saturation degree at the end of consolidation to a void ratio of $\approx 1.0$.

\begin{tabular}{|c|c|c|c|}
\hline Material & $\mathbf{w}$ & $\boldsymbol{\theta}$ & $\mathbf{S}_{\mathbf{r}}$ \\
\hline Tailings & 0.56 & $0.49 \pm 0.012$ & $0.97 \pm 0.043$ \\
\hline Coal fraction & 0.62 & $0.46 \pm 0.012$ & $0.99 \pm 0.043$ \\
\hline
\end{tabular}


Figures 4 to 5 highlight a number of differences between the materials tested. As the proportion of coal increases in a material, the SWRC generally shifts towards lower values of volumetric water content at any given suction. This could be interpreted as an effect of hydrophobicity or simply by larger particle/pore sizes present as coal content increases (see Figure 2).

Second, the suction at which water content begins to decrease rapidly on the drying path (typically the air entry value - AEV - for most soils) reduces as the coal content increases in a material. Similar to the first observation, this is likely due to the larger dominant pore size associated with higher coal content materials.

Third, materials containing macerals have a steeper negative gradient after the apparent "AEV", when compared to the mineral fraction. However again, this could simply be due to the larger particle/pore sizes of these materials.

Fourth, the materials containing coal appear to desaturate at very low suctions when compared to the mineral fraction, going from a saturated condition post consolidation to a $\mathrm{Sr}$ of less than 0.9 before a suction of $10 \mathrm{kPa}$. This raises uncertainty as to the true AEV, since the change in slope of the SWRC for coal containing materials does not coincide with the departure from a $\mathrm{Sr}$ value of 1 . This observation is unusual, as it is uncommon for fine grained soils with a monomodal PSD to be unsaturated at such a low suction, particularly given its high proportion of fine particles and being prepared from a slurry. Note that the desaturation under low suction cannot be explained by capillarity. Indeed, using the Young-Laplace equation, a suction of $10 \mathrm{kPa}$ corresponds to pores with an entrance diameter larger than $20 \mu \mathrm{m}$ (assuming a contact angle between $0-45^{\circ}$, which is common for mineral soils [12]). However, Figure 3 clearly shows there are no pores this large, and it was estimated a contact angle of $70^{\circ}-85^{\circ}$ would be necessary to achieve desaturation for the entrance pore sizes present in the coal containing materials. Such a high value of contact angle is possible for coal $[4,7]$ and indicates an effect of localised hydrophobicity.

\subsection{Water permeability results}

The water permeability results for the three materials are shown in Table 3.

Table 3. Saturated water permeability of the materials.

\begin{tabular}{|c|c|c|}
\hline Material & Void ratio & $\begin{array}{c}\text { Permeability } \\
(\mathbf{m} / \mathbf{s})\end{array}$ \\
\hline Tailings & 0.98 & $1.3 \times 10^{-8}$ \\
\hline $\begin{array}{c}\text { Coal } \\
\text { fraction }\end{array}$ & 1.0 & $2.54 \times 10^{-8}$ \\
\hline $\begin{array}{c}\text { Mineral } \\
\text { Fraction }\end{array}$ & 1.0 & $1.27 \times 10^{-9}$ \\
\hline
\end{tabular}

The saturated water permeability of a material was found to increase with increasing coal content. This finding correlates with the GSD and PSD results, as the larger particle/pore sizes of the coal containing materials would likely lead to an increased permeability. The coal fraction has a $95 \%$ higher permeability than the tailings. However, when considering a simple estimate of permeability (a squared relationship to pore size [13]), a $32 \%$ larger dominant pore size (from Figure 3) is expected to only provide a $74 \%$ increase in permeability. This discrepancy is likely due to differences in pore tortuosity and connectivity which is not captured in the simple permeability estimate, or differences in the PSD due to the different preparation procedure used. However, it is also possible that local hydrophobicity is partly responsible for a larger permeability in the coal. In any case, the interaction of coal with water, and the effect it has on permeability need to be better understood before drawing definitive conclusions.

\section{Conclusions}

Hydraulic and retention properties were determined for a coal tailing and separated maceral and mineral fractions. The results found that the coal within tailings has a significant effect on the SWRC and saturated water permeability.

Most effects observed in the SWRC (due to coal) could be explained partly by the grain size distribution and pore size distribution differences between each material. However, the unsaturated state of the materials containing coal at low suctions is unusual given the proportion of fine grains in the materials and the preparation procedure (consolidated from slurry) and could not be explained by the microstructural differences. It is suggested that the desaturation at low suction may be due to the increased hydrophobicity of coal caused by localised hydrophobic areas on coal molecules.

\section{References}

1. R.M. Davidson. Molecular structure of coal. Coal Science. 1982.

2. W.R. Grimes. The Physical Structure of Coal. Coal Science. 1982.

3. J. Karas, R.J. Pugmire, W.R. Woolfenden, D.M. Grant, S. Blair. Comparison of Physical and Chemical Properties of Maceral Groups Separated By Density Gradient Centrifugation. International Journal of Coal Geology 5, 315 (1985)

4. J.A. Gutierrez-Rodriguez, R.J. Purcell, F.F. Aplan. Estimating the hydrophobicity of coal. Colloids and Surfaces 12, 1 (1984)

5. R. Kaji, Y. Muranaka, H. Miyadera, Y. Hishinuma. Effect of Electrolyte on the Rheological Properties of Coal-Water Mixtures. 33, 11 (1987)

6. N. Wang, M. Sasaki, T. Yoshida, T. Kotanigawa. Estimation of coal hydrophilicity by flow microcalorimetry. 1998

7. B.J. Arnold, F.F. Aplan. The hydrophobicity of coal 
macerals. Fuel 68, 651 (1989)

8. B.K. Parekh, F.F. Aplan. The critical surface tension of wetting of coal. Recent Developments in Separation Science: Volume 4. West Palm Beach, FL, FL: CRC Press, 1978: 107-13.

9. E. Jorjani, S. Esmaeili, M.T. Khorami. The effect of particle size on coal maceral group's separation using flotation. Fuel 114, 10 (2013)

10. E.F. Ethington. Interfacial contact angle measurements of water, mercury, organic liquids on quartz, calcite, montmorillonite. Construction and Building Materials 583 (1990)

11. X. Liu, O. Buzzi. Use of hand-spray plaster as a coating for soil bulk volume measurement. Geotechnical Testing Journal 37, (2014)

12. M. Hajnos, A. Calka, G. Jozefaciuk. Wettability of mineral soils. Geoderma 206, 63 (2013)

13. R.G. Shepherd. Correlations of Permeability and Grain Size. Groundwater 27, 633 (1989) 